\title{
STATISTICAL PROCESS CONTROL (SPC) OF DAMAGE METRICS IN THE IMPEDANCE-BASED STRUCTURAL HEALTH MONITORING
}

\author{
Quintiliano Siqueira Schroden NOMELINI ${ }^{1}$ \\ José Waldemar da SILVA ${ }^{1}$ \\ Carlos Alberto GALLO ${ }^{2}$ \\ Roberto Mendes FINZI NETO ${ }^{2}$ \\ José dos Reis Vieira de MOURA JUNIOR ${ }^{3}$ \\ Julio Endress RAMOS ${ }^{4}$
}

- ABSTRACT: Statistical Process Control (SPC) stands out for the use of control charts and for repeatability and reproducibility $(\mathrm{R} \& \mathrm{R})$ techniques. This work aimed at its applications in the aspects of pre-processing of structural monitoring. The experiment was carried out in a completely randomized design (CRD) with two sources of variation: eight aluminum beams with piezoelectric patches and five types of damage (D1 = baseline, D2 =0.6g, D3 = 1.1g, D4 = 1.6g, D5 = 2.2g). All measurements were gathered at $30^{\circ} \mathrm{C}$ and with 20 repetitions for each condition case, producing a damage metric. In the R\&R study, a low variation of repetition was observed (9.84\%), but a high reproducibility $(72.39 \%)$, representing that the damage metrics were similar for each situation, but a high variation among beams and damages. Based on this evaluation, the control charts helped to verify in which beams and damages these greatest variabilities were found. Concluding, the control charts for mean and individual measures as well as the R\&R study were interesting tools for raw data preprocessing step for measurement error detection.

- KEYWORDS: Control carts; R\&R study; structural health monitoring.

\section{Introduction}

According to Montgomery (2016), SPC (Statistical Process Control) is a powerful collection of problem-solving tools, useful in achieving process stability and improving capability by reducing variability.

SPC makes use of simple statistical techniques to detect changes in the behavior of the process, allowing production management to implement appropriate adjustments as soon as possible. The analysis of this variation makes it possible to compare the planned goal from the past performance of the process (NOMELINI, 2007).

\footnotetext{
${ }^{1}$ Universidade Federal de Uberlândia - UFU, Escola de Matemática, CEP: 38400-902, Uberlândia, MG, Brasil. E-mail: quintiliano.nomelini@ufu.br; zewaldemar@ufu.br

${ }^{2}$ Universidade Federal de Uberlândia - UFU, Escola de Engenharia Mecânica, CEP: 38400-902, Uberlândia, MG, Brasil, E-mail: gallo@ufu.br; finzi@ufu.br

${ }^{3}$ Universidade Federal de Goiás - UFG, Instituto de Matemática e Tecnologias, CEP: 75704-020, Catalão, GO, Brasil, E-mail: zereis@ufg.br

${ }^{4}$ Petróleo Brasileiro S.A. - PETROBRAS, CENPES, CEP: 21941-915, Rio de Janeiro, RJ, Brasil, E-mail: julio.ramos@petrobras.com.br
} 
The main objective of SPC is to quickly detect the occurrence of special causes of process changes, so that process investigation and corrective action can be carried out before many defective units are manufactured. It may not be possible to completely eliminate the variability, but the control chart tool is able to reduce this variability as much as possible (MONTGOMERY, 2016). Among several tools of the SPC, control charts are undoubtedly the most important.

A process will never produce exactly the same item twice. But these variations are often so small that appropriate instruments for measurement and control are needed.

Thus, the real world has variation as a fundamental part and production processes are also subject to it. However, variation has a paradoxical aspect: too much variation is generally associated with losses, inefficiency and lack of control, while too little variation can lead to stagnation (ALMAS, 2003).

Almas (2003) also states that variation is often interpreted differently, according to the point of view: a biologist can see variability as a beneficial factor in the evolutionary process of a certain species, whereas an engineer, analyzing his/her production flow, can conclude that variability is the main cause of non-conformities in his products. Thus, it is necessary to understand variation and its role in order to achieve quality and provide innovation and growth on an ongoing basis.

Montgomery (2016) states that, in any production process, regardless of how well planned or carefully maintained it is, a certain amount of inherent or natural variability will always exist.

According to Veit (2003), variation is universal and it exists in any process. The same author also says that it exists inside materials, equipment condition, working and inspection methods which are ultimately the causes of the defects.

Variability is the difference between the units produced. If this variability is large, the differences are easily observed, but if they are small, they are not. The process can have natural variability, which are small disturbances, in which nothing can be done since it is practically impossible to produce two identical products or services.

Kume (1993) defines that when the manufacturing process is considered from the point of view of quality variation, the process can be understood as a sum of the causes of variation. The same author states that the explanation of the changes in the quality characteristics of the products, originating defective or non-defective products, is exactly in the variability.

Deming's (1990) contribution in this field was very important because he always highlighted the importance of knowing how to distinguish common causes from special causes. According to him, it is a common mistake to attribute a variation to a special cause, instead of a cause belonging to the system (common causes) and vice versa. Deming claims that $94 \%$ of problems and possibilities for improvement are based on common causes and only $6 \%$ are based on special causes.

According to Nomelini (2012), the methods of analysis of the component variability of a system can be exemplified by the techniques of repeatability (Repe) and reproducibility (Repro), i.e., the R\&R study. This analysis is based on the definitions of these two terms to analyze the accuracy of the measurements.

In general, the random cause of variation is a source of unpredictable variation, inherent to the process, that affects all individual values of a specific feature from the measurement. This type of variation is directly related to the random measurement error from several causes, promoting a system of random causes with none overlapping over the 
other. In this way, for instance, accurate measurements of an observation gathered by different individuals, and concerning to the reproducibility of the measurement process, are not exactly the same. On the other hand, there is a variability in the measurements gathered from a measuring instrument while collected several times by same operator (repeatability of a measurement process). Once each individual measurement differs from each other, grouped form a probability distribution defined by shape (distribution type), center of distribution and variability of individual values. Thus, the variation due to random causes can only be reduced by changing the process itself, redesigning it.

Abnormal events cause predictable variations in the process due to their abnormality in the measured data. This type of variation is associated with the systematic measurement error. The complete deletion of special causes of variation must be done in order to have a stable process, an essential condition for implementing improvements in this process.

According to Montgomery (2016), the natural variability of the process is called stable system of random causes. He also states that a process that operates only with the random causes of variation is under statistical control and the process that operates in the presence of special causes is out of control.

In this context, this contribution aims to apply such methods to a data set from an experiment to estimate and infer about the structural changes of steel beams via electromechanical impedance signatures. In order to avoid it happens without external interference, a pre-processing study was conducted via SPC.

In the following sections are covered some descriptions of the experiment as well as concepts and results. First, it is presented the proposed experiment in the thermic chamber by using beam samples and the damage metric used to evaluate them. Then it is reviewed shortly some concepts of repeatability and reproducibility measures by the model of analysis of variance and control charts. Further, results will be presented proving that besides some temperatures have better repeatability and reproducibility, SPC is still a good approach for descriptive analysis and data pre-processing.

\section{Methodology}

Initially, an experiment was performed to understand the behavior of damage detection in aluminum beams using the electromechanical impedance method. An EPL-4H climatic temperature and humidity control chamber of the Platinous series was used to control the temperature effect. This chamber is installed in the Structural Mechanics Laboratory of the School of Mechanical Engineering at the Federal University of Uberlandia (UFU-FEMEC-LMEst). This chamber uses a BTHC (Balanced Temperature and Humidity Control) system and has a working volume of $900 \mathrm{~L}$, with a temperature range between -35 to $180{ }^{\circ} \mathrm{C}\left( \pm 0.5{ }^{\circ} \mathrm{C}\right)$. Its heating rate is $5.2{ }^{\circ} \mathrm{C} / \mathrm{min}$ while cooling is $1.4{ }^{\circ} \mathrm{C} / \mathrm{min}$. Its humidity varies between 10 and $98 \%$ relative humidity $( \pm 3 \%)$. The BTHC system performs the thermodynamic balance between temperature and humidity for the control of parameters. Eight aluminum beams, $500 \mathrm{~mm}$ long, $38 \mathrm{~mm}$ wide and $3.2 \mathrm{~mm}$ thick, were used in the experiment. In each one a PZT patch (piezoelectric ceramic) $1 \mathrm{~mm}$ thick and 20 $\mathrm{mm}$ diameter was bonded at $100 \mathrm{~mm}$ from the edge of the structure. Figure 1 shows in detail the PZT patch used in each specimen. The baseline measurements were gathered measuring this initial structure scheme. Further, damaged cases were measured by the addition of mass following this: D1 = baseline, D2 $=0.6 \mathrm{~g}, \mathrm{D} 3=1.1 \mathrm{~g}, \mathrm{D} 4=1.6 \mathrm{~g}$ and D5 $=2.2 \mathrm{~g}$. Figure 2 
illustrates the position of the added mass bonded on the beams. Then, it was considered a completely randomized design (CRD) with two factors: PZT (eight beams) and Damage (five levels) and 20 repetitions for each case. All experiments were conducted at the following temperatures $-10,0,10,20,30,40$ and $50^{\circ} \mathrm{C}$. However, in this contribution it was decided to present in greater detail the results obtained at temperature $30{ }^{\circ} \mathrm{C}$ due to the low variation in its R\&R study.

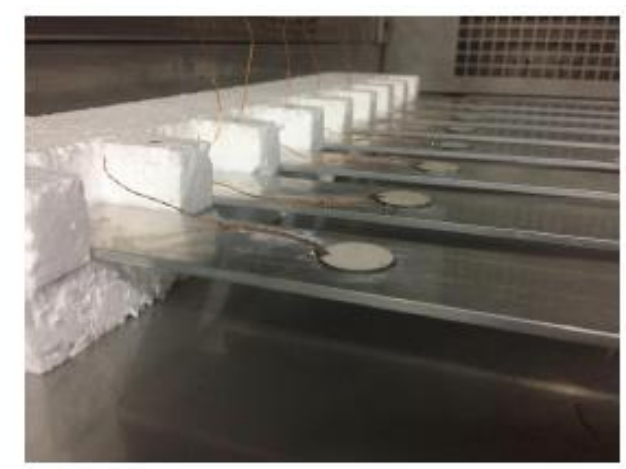

Figure 1 - PZT patches bonded on beams.

For each gathered electromechanical impedance signature was used the real part to calculate the damage metric according to Peairs (2006), presented in Eq. (1) as a new definition of the root mean square deviation (RMSD). Several RMSD alike equations are proposed by him and the RMSD5 is the chosen one as the best option for impedance method. According to the technique, the real part of the impedance signature is responsible for the structural aspects while imaginary is correlated to the electrical features of the PZT patch.

$$
R M S D 5=\sqrt{\sum_{i=1}^{n}\left(\frac{\frac{\left(R e\left(\bar{z}_{1, i}\right)-R e\left(z_{2, i}\right)\right)^{2}}{S_{Z_{1, i}}}}{n}\right)}
$$

where $\operatorname{Re}\left(\bar{Z}_{1, i}\right)$ is the mean of the real part of the impedance measurement without damage (baseline) at a frequency $i, \operatorname{Re}\left(Z_{2, i}\right)$ is the real part of the measurement at a frequency $i$ for a new structure configuration (with damage), $n$ is the total number of frequency points used in the comparison. The standard deviation of each point of the baseline signature $S_{Z_{1, i}}$ is included in order to make the metric less sensitive to changes in the impedance signal due to changes in the environment (and not properly associated with any damage). 


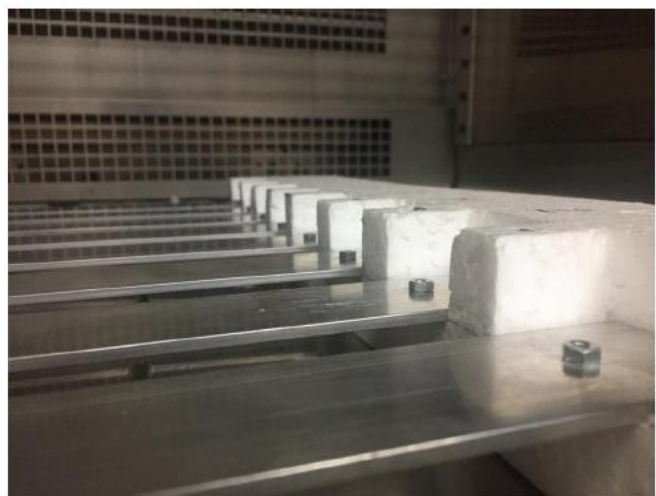

Figure 2 - Damage 1 and its mass addition bonded on the beam.

\subsection{Repeatability and reproducibility measures by the model of analysis of variance}

Due to the lack of reference values for the standard deviations of repeatability and reproducibility they become difficult to be interpreted. Thus, the method of estimating variations in repeatability and reproducibility from the analysis of variance is more appropriate because the total variability of an experiment is used as a reference in a completely randomized design. This case considered the effect of the interaction between damage and PZT patch/beam (Table 1). Therefore, the results of the damage metrics by PZT patch and by damages were expressed by Eq. (2):

$$
y_{i j k}=\mu+\alpha_{i}+\beta_{j}+\gamma_{i j}+\varepsilon_{i j k}
$$

where $i=1,2, \ldots, n_{I} ; j=1,2, \ldots, n_{J} ; k=1,2, \ldots, n_{K}, y_{i j k}$ is the RMSD5 damage metric obtained from the $\mathrm{i}$-th damage, made by the $\mathrm{j}$-th PZT patch in the $\mathrm{k}$-th repetition; $\mu$ is the general RMSD5 average of damage; $\alpha_{i}$ is the effect of the $\mathrm{i}$-th damage; $\beta_{j}$ is the effect of the j-th PZT patch; $\gamma_{i j}$ is the effect of the interaction between j-th PZT patch and i-th damage condition; $\varepsilon_{i j k}$ is the error obtained by the differences between RMSD5 of the same damage, by the same PZT patch; $n_{i}$ is number of damage cases; $n_{j}$ is the number of PZT patches and $n_{k}$ is the number of repetitions.

The random effects and variances are respectively: $\alpha_{i}, \beta_{j}, \gamma_{i j}, \varepsilon_{i j k}$ and $\sigma_{i}^{2}, \sigma_{j}^{2}, \sigma_{I}^{2}, \sigma_{E}^{2}$. Then, the random variable $Y$ has the total variance defined by Eq. (3).

$$
\operatorname{VAR}(Y)=\sigma_{i}^{2}+\sigma_{j}^{2}+\sigma_{I}^{2}+\sigma_{E}^{2}
$$


According to Automotive Industry Action Group (AIAG) (2002), Pinto Júnior (2003) and Nomelini (2012), the method of analysis of variance (Table 1) consists of estimating the components of variance by the Hicks method (1973) given by expression (2).

Table 1 - Analysis of variance in a completely randomized design with two factors, PZT patch and damage case, with their respective degrees of freedom (DF), sum of square (SS), mean square (MS), components of variance and F statistic

\begin{tabular}{|c|c|c|c|c|c|}
\hline $\begin{array}{l}\text { Sources of } \\
\text { Variation }\end{array}$ & DF & SS & MS & $\mathrm{E}(\mathrm{MS})$ & F Statistic \\
\hline Damage & $n_{I}-1$ & SSDamage & MSDamage & $\sigma_{E}^{2}+n_{K} \sigma_{I}^{2}+n_{K} n_{J} \sigma$ & $\frac{T_{i} \mathcal{H} S_{\text {Damage }}}{M S_{I}}$ \\
\hline PZT & $n_{J}-1$ & SSPZT & MSPZT & $\sigma_{E}^{2}+n_{K} \sigma_{I}^{2}+n_{K} n_{I} \sigma$ & $\sigma_{j}^{2} \frac{M S_{P Z T}}{M S_{I}}$ \\
\hline Damage*PZT & $\begin{array}{l}\left(n_{I}-1\right) \\
\left(n_{J}-1\right)\end{array}$ & SSI & MSI & $\sigma_{E}^{2}+n_{K} \sigma_{I}^{2}$ & $\frac{M S_{I}}{M S_{E}}$ \\
\hline $\begin{array}{l}\text { Repeatability } \\
\text { (Residue) }\end{array}$ & $n_{I} n_{J}\left(n_{K}-1\right)$ & SSE & MSE & $\sigma_{E}^{2}$ & \\
\hline Total & $n-1$ & $\mathrm{SST}$ & & $\sigma_{T}^{2}$ & \\
\hline
\end{tabular}

The sums of total squares, damage and PZT and the mean squares are given by the usual expressions (STEEL and TORRIE, 1981; NETER et al., 1985):

$$
\begin{aligned}
S S_{T} & =\sum_{i=1}^{n_{I}} \sum_{j=1}^{n_{J}} \sum_{k=1}^{n_{K}}\left(y_{i j k}^{2}-\bar{y}_{\ldots .}\right)^{2} ; \\
S S_{\text {Damage }} & =n_{J} n_{K} \sum_{i=1}^{n_{I}}\left(\bar{y}_{i . .}-\bar{y}_{. . .}\right)^{2} \\
S S_{P Z T} & =n_{I} n_{K} \sum_{j=1}^{n_{J}}\left(\bar{y}_{. j .}-\bar{y}_{\ldots .}\right)^{2} ; \\
S S_{\text {Re sidue }} & =\sum_{j=1}^{n_{J}} \sum_{i=1}^{n_{I}} \sum_{k=1}^{n_{K}}\left(y_{i j k}-\bar{y}_{i j .}\right)^{2} ; \\
S S_{\text {Int }} & =n_{K} \sum_{j=1}^{n_{J}} \sum_{i=1}^{n_{I}}\left(\bar{y}_{i j .}-\bar{y}_{i . .}-\bar{y}_{. j .}+\bar{y}_{\ldots . .}\right)^{2} .
\end{aligned}
$$

Finally, the components of variance were estimated with the mean square of the residue (error) being an unbiased estimator for the repeatability variance, represented by:

$$
\hat{\sigma}_{E}^{2}=M S_{E}=\hat{\sigma}_{r}^{2} ; \text { repeatability variance }
$$


defined:

From expected value of the mean square estimated by Hicks (1973) can be

$$
\begin{aligned}
\hat{\sigma}_{E}^{2}+n_{K} \hat{\sigma}_{I}^{2}=M S_{I} \rightarrow \hat{\sigma}_{I}^{2}=\frac{M S_{I}-M S_{E}}{n_{K}} ; \text { variance of the iteration } \\
\hat{\sigma}_{E}^{2}+n_{K} \hat{\sigma}_{I}^{2}+n_{K} n_{I} \hat{\sigma}_{j}^{2}=M S_{j} \rightarrow \hat{\sigma}_{j}^{2}=\frac{M S_{j}-M S_{I}}{n_{K} n_{I}} ; \text { PZT variance } \\
\hat{\sigma}_{E}^{2}+n_{K} \hat{\sigma}_{I}^{2}+n_{K} n_{J} \hat{\sigma}_{i}^{2}=M S_{i} \rightarrow \hat{\sigma}_{i}^{2}=\frac{M S_{i}-M S_{I}}{n_{K} n_{J}} ; \text { damage variance } \\
\hat{\sigma}_{R}^{2}=\hat{\sigma}_{j}^{2}+\hat{\sigma}_{I}^{2} ; \text { reproducibility variance } \\
\hat{\sigma}_{R \& R}^{2}=\hat{\sigma}_{r}^{2}+\hat{\sigma}_{R}^{2} ; \text { total variance of the R\&R study } \\
\hat{\sigma}_{T}^{2}=\hat{\sigma}_{R \& R}^{2}+\hat{\sigma}_{i}^{2} ; \text { total variance }
\end{aligned}
$$

The total variability of each factor in the model is represented in Table 2.

Table 2 - Percentage of contribution of total variation

\begin{tabular}{ccc}
\hline Sources of Variation & Variances & Contribution (\%) \\
\hline Repeatability & $\hat{\sigma}_{r}^{2}$ & $100 *\left(\hat{\sigma}_{r}^{2} / \hat{\sigma}_{T}^{2}\right)$ \\
Reproducibility & $\hat{\sigma}_{R}^{2}$ & $100 *\left(\hat{\sigma}_{R}^{2} / \hat{\sigma}_{T}^{2}\right)$ \\
\hline R\&R Total & $\hat{\sigma}_{R \& R}^{2}=\hat{\sigma}_{r}^{2}+\hat{\sigma}_{R}^{2}$ & $100 *\left(\hat{\sigma}_{R \& R}^{2} / \hat{\sigma}_{T}^{2}\right)$ \\
\hline PZT & $\hat{\sigma}_{j}^{2}$ & $100 *\left(\hat{\sigma}_{j}^{2} / \hat{\sigma}_{T}^{2}\right)$ \\
Damage* PZT & $\hat{\sigma}_{I}^{2}$ & $100 *\left(\hat{\sigma}_{I}^{2} / \hat{\sigma}_{T}^{2}\right)$ \\
\hline Within (Damage) & $\hat{\sigma}_{i}^{2}$ & $100 *\left(\hat{\sigma}_{i}^{2} / \hat{\sigma}_{T}^{2}\right)$ \\
\hline Total & $\hat{\sigma}_{T}^{2}$ & 100.0 \\
\hline
\end{tabular}

\subsection{Control charts}

In 1924, Dr. Walter A. Shewhart presented control charts for the first time as a method for analyzing and adjusting the variation of a process as a function of time. When goods or services are produced, their characteristics will vary due to factors that make up the process. These variations can be differences among machines, changes in environmental 
conditions, variations among batches of raw material, different suppliers and others. Although considerable effort is specifically directed towards controlling variability in each of these factors, there will always be variability in the finished product of each process in a company. Therefore, it is important that this variability is also controlled so that good quality products can be obtained.

The control chart is a statistical technique used to measure and analyze the behavior of a process. It is a chart consisting of central line (CL), lower control limit (LCL), upper control limit (UCL) and values of the parameter of interest represented sequentially over the time. They represent the current state of a process. The central line represents a central or mean value of the measurements of the process characteristic. Shewhart structured the 3 Sigma control limits of the central line, where sigma $\sigma$ is the standard deviation, so that there is a minimal economic loss (DEMING, 1990). If all the values of the parameter under examination are within the control limits, without any abnormal pattern, the process presents only random causes of variation and is said to be in a statistically controlled state, being considered a stable process. Otherwise, if the process also has special causes of variation is considered as out of statistical control or an unstable process. In this case, the analysis of causes must be done and corrective actions taken to achieve the stability of the process. If the process is under control, all marked points must have an essentially random pattern. There are methods to look for patterns of nonrandomness which help the applicability of control charts and, if discovered, lead to improved process performance.

The interpretation of the control charts and the definition of the moment when the process is out of control are made by examining the occurrence of non-randomness patterns. The identification and elimination of these special causes may reduce the variability of the process, which is the objective of the SPC, and will also bring the process to a condition of statistical control. Some methods to look for patterns of non-randomness, according to Werkema (1995): Points outside the limits of controls; Cyclic or periodicity patterns; Process level shift or sequence; Trend and Mix or approximation of control limits.

According to Montgomery (2016), the mean and standard deviation chart is widely used when you have large sample sizes $n$, such as, for example, $n>10$. The $\sigma$ estimation by the amplitude method loses statistical efficiency for moderate and large sample sizes. Below are the limits for the control charts $\bar{X}$ in $S$, respectively.

$\mathrm{e}$

$$
\begin{aligned}
& U C L=\overline{\bar{x}}+A_{3} \bar{s} \\
& C L=\overline{\bar{x}} \\
& L C L=\overline{\bar{x}}-A_{3} \bar{s}
\end{aligned}
$$

$$
\begin{aligned}
& U C L=B_{4} \bar{s} \\
& C L=\bar{s} \\
& L C L=B_{3} \bar{s}
\end{aligned}
$$

where $\bar{s}$ is the mean standard deviation; $\bar{x}$ is the mean of the means and $A_{3}, B_{3}$ e $\mathrm{B}_{4}$ are constants found in Appendix IV in Montgomery (2016).

The control chart for individual measurements is used to monitor processes with sample sizes $n=1$, i.e., samples that consist of individual measurements. Then, it is necessary to estimate some parameters for the construction of the control chart limits. This 
case is slightly different from the previous cases. Once it is not possible to build a $\bar{X}-A M$ chart, because there are not enough observations to estimate $\overline{\bar{x}}$, a $X-A M$ chart is then made, in which $A M$ means moving range, which is given by the formula:

$$
A M_{i}=\left|x_{i}-x_{i-1}\right| ; \quad i=2, \ldots, m,
$$

where $m$ is the number of individual observations gathered.

Note that each sample has a single observation for the quality variable to be monitored, and neither possible to estimate $\overline{\bar{x}}$, nor $A M$ for the first observation. Therefore, it will be estimated the process average as the sample mean and the variability of the process by moving range (AM). Thus, the control limits for the $X-A M$ chart are shown below, according to Montgomery (2016):

$$
\begin{aligned}
& \mathrm{UCL}=\bar{x}+3 \frac{\overline{A M}}{d_{2}} \\
& C L=\bar{x} \\
& L C L=\bar{x}-3 \frac{\overline{A M}}{d_{2}}
\end{aligned}
$$

This, for the mean chart and below for the moving range chart.

$$
\begin{aligned}
& \mathrm{UCL}=D_{4} \overline{A M} \\
& C L=\overline{A M} \\
& L C L=D_{3} \overline{A M}
\end{aligned}
$$

The constants $d_{2}, D_{3}$ e $D_{4}$ found in Appendix IV in Montgomery (2016) and $\overline{A M}$ is obtained by:

$$
\overline{A M}=\sum_{i=2}^{m} \frac{A M_{i}}{(m-1)} .
$$

\section{Results and discussions}

From the study of variability of the damage metric RMSD5, using the analysis of variance method, the percentage of contribution of the variation of repeatability and reproducibility was estimated in relation to the total variation of the data, including the variation related to the PZTs and the interaction PZTs with damage (Table 3). Thus, it can be observed that regardless of temperature, the percentage of contribution to the total variation was always higher in the $R \& R$ study for reproducibility, with the lowest repro being for temperature -10 degrees and the highest for temperature 0 degrees. For the repe, the lowest percentage found was 10 degrees and the highest was -10 degrees. In general, 
the lower the R\&R values, the better the results of the experiment. For the temperature of 30 degrees, the lowest percentage of $R \& R(82.23 \%)$ was observed. In this way, analyzing the repro it is noticed that even though the PZTs have been assembled in a similar way and put to be monitored in the same frequency ranges, they have different behaviors in the impedance signatures and also in the subsequent transformation of the impedance to a damage metric. There is also a high percentage of variation in the interaction between PZTs and damage, which means that the different PZTs, in terms of damage levels, are taking different measures in relation to damage metrics, so it is necessary to study within each PZT damage level.

In general, in the analysis of the repe, the results had low values of percentages of contribution of the variances, except for temperature -10 degrees. This shows how much each PZT patch has shown consistency of its results, i.e., the low variation between its measures for the same damage. Thus, they repeat the same reading of their measurements in similar situations.

Table 3 - Contribution percentages of the estimated variances in relation to the total variation for the RMSD5 damage metric at each temperature $(-10,0,10,20,30$, 40 and 50 ) in the R\&R study

\begin{tabular}{ccccc}
\hline & Temp.-10 & Temp.0 & Temp.10 & Temp.20 \\
\cline { 2 - 4 } Sources of Variation & $\% \mathrm{C}$ & $\% \mathrm{C}$ & $\% \mathrm{C}$ & $\% \mathrm{C}$ \\
\cline { 2 - 4 } Repeatability & 28.75 & 2.06 & 1.63 & 7.42 \\
Reproducibility & 63.32 & 93.58 & 84.58 & 76.59 \\
R\&R Total & 92.07 & 95.64 & 86.21 & 84.01 \\
PZT & 25.65 & 19.19 & 26.80 & 23.07 \\
PZT*Damage & 37.67 & 74.39 & 57.78 & 53.52 \\
Within (Damage) & 7.93 & 4.36 & 13.79 & 15.99 \\
Total & 100.00 & 100.00 & 100.0 & 100.0 \\
\hline & Temp.30 & Temp.40 & Temp.50 & \\
\cline { 2 - 4 } Sources of Variation & $\% \mathrm{C}$ & $\% \mathrm{C}$ & $\% \mathrm{C}$ & \\
\hline Repeatability & 9.84 & 9.43 & 5.27 & \\
Reproducibility & 72.39 & 78.06 & 78.64 & \\
R\&R Total & 82.23 & 87.49 & 83.91 & \\
PZT & 24.23 & 28.89 & 39.75 & \\
PZT*Damage & 48.16 & 49.17 & 38.89 & \\
Within (Damage) & 17.77 & 12.51 & 16.09 & \\
Total & 100.0 & 100.0 & 100.0 &
\end{tabular}

$\% \mathrm{C}$ : Contribution percentages in relation to the total variation; Temp.: temperature; R\&R: repeatability and reproducibility. Results obtained using Minitab 14® software.

Since the lowest value for $\mathrm{R} \& \mathrm{R}$ was at a temperature of 30 degrees, it was decided to detail the variation of repe and repro for that case only. It can be seen that the variation of the RMSD5 damage metric among for the damage in the first four PZTs was not very 
large. Then, there was a greater variation between the damage in PZTs 5 onwards, and thus, being able to better distinguish between the different added masses placed as damage to the beams, this difference appears in the boxplot between damages (Figure 3). It is important to note that in this case the chart shows the damage independent of the PZTs, as can be seen in the interaction chart (Figure 3). Thus, this is one additional result that justifies the measurements at temperature $30{ }^{\circ} \mathrm{C}$, because have both less variation in $\mathrm{R} \& \mathrm{R}$ also have greater variation between the damages in this case.

The control charts of the R\&R study (Figure 3) were separated to compare among all PZTs the average displacement of the RMSD5 damage metric and its mean variability from the mean standard deviation. It was observed that the PZTs 2 and 3 had the average displacement between the damages ( $1=$ baseline, $2=0.6 \mathrm{~g}, 3=1.1 \mathrm{~g}, 4=1.6 \mathrm{~g}$ and $5=2.2 \mathrm{~g}$ ). In other PZTs, a slightly greater average displacement between the damage in PZT1 and PZT4. From PZT5 to PZT8 both the mean and the standard deviation started to have greater variations between the damages. However, it is expected that only the mean values of the damage metrics would increase according to the defined damages. In general, it was observed that the mean damage metric values increased from damage 1 to damage 4 , but oscillated between increasing or decreasing in damage 5 (Figure 3). PZTs 4 and 7 were better at discriminating between the damage metrics, since all damages 2 to 5 showed an increasing relationship to the baseline (damage 1). PZTs 1, 2 and 3, on the other hand, seemed to be the worst in distinguishing between the formulated damages. The other PZTs can also be considered efficient even with the oscillation in the average of the last damage metric, since these different behaviors between PZTs were to be expected.

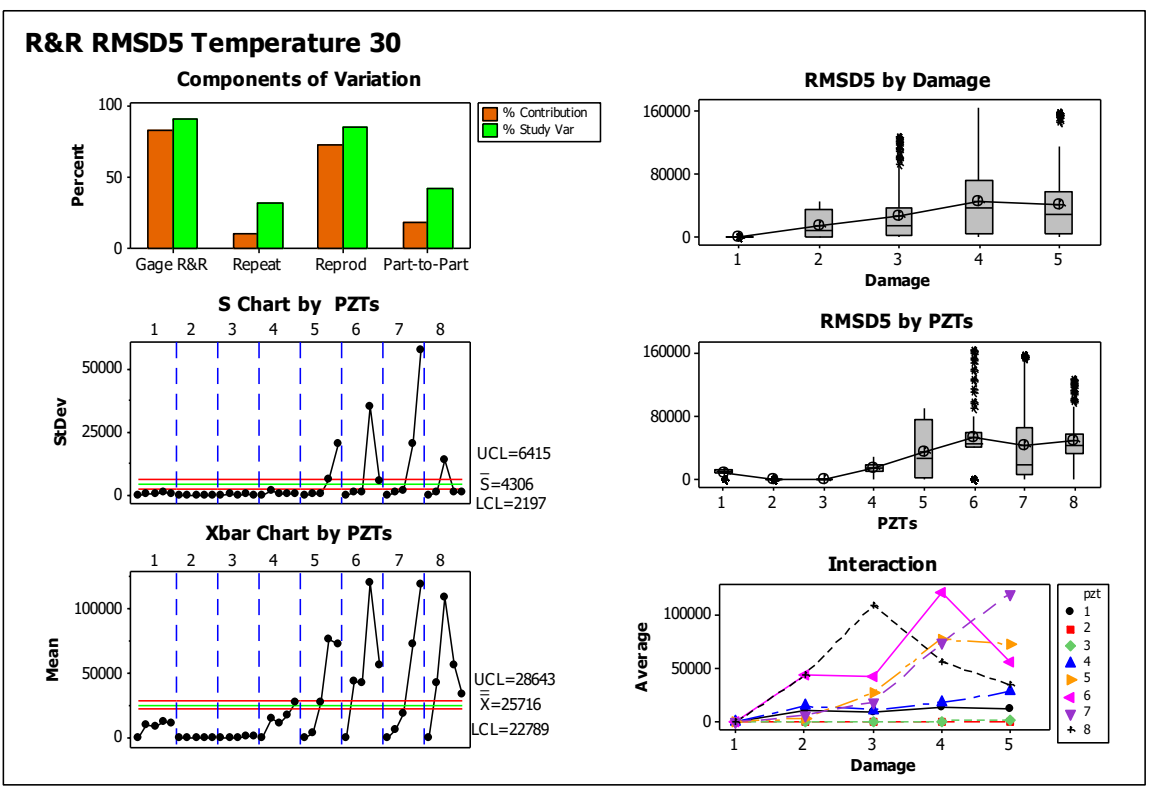

Figure 3 - Additional graphs of the R\&R study for RMSD5 damage metric for temperatures of 30 degrees, including descriptive boxplot by PZT and damage, variation component, interaction and control charts of the mean and standard deviation. Results obtained using Minitab 14® software. 
Observing separately at the control charts for mean and standard deviation in each PZT at a temperature of 30 degrees Celsius, there is a difference in relation to the charts when all PZT are compared together. From the PZT4 onwards, the measures of the damage metrics change their values dramatically with a much larger dimension or scale. Thus, he hid the difference between the damage in PZTs 1, 2 and 3, suggesting that all the averages of the damage metric were the same (Figure 3). On the other hand, in Figure 4a-h, without the interference of the scale, the actual displacement of the mean damage metric is observed.

It can be seen in the mean, Figure 4a, PZT1, that the lower and upper control limits were very close. Still, all averaging points outside these limits. As the differences between the damage metrics 2 to 5 were very small (low variability) and only the damage 1 (baseline) was much lower than the other damages, this difference brought the average line closer to damages 2 to 5 . In relation to the variability concludes that only in damages 1 and 4 the variation was greater, taking the standard deviation outside the control limits, with the variation of damage 1 , baseline, being very small close to zero and damage 4 very high close to 750. Concerning to the increase of damages 2 to 5, a small difference is observed between damage 2 and 3, which increases to damage 4, the latter being close to damage 5 . Even though the difference is small, there is a growth in damage scale, damage 2 and 3 closer and slightly above the baseline, damage 4 and 5 close to each other as well and more distant from the baseline, as expected due to the increase in addition of masses that refer to the increased damage to the structure.

PZT2 in Figure 4b illustrates the opposite of PZT1. Although the control limits of the mean are also close to each other, the differences between the damage metrics 1 to 4 were very small (low variability) and only damage 5 (greater mass addition) was greater than the others. In this way, the control limits were pulled to the bottom of the metric. Regarding the variability, it is observed that only damage 4 had greater variability, but even so it was not enough to increase the mean damage. Concerning to damage growth 1 to 4 , a very small difference is observed, showing no discrimination between damage and baseline, except for damage 5. Thus, PZT2 was not efficient to detect damage from the impedance measurements. Some assumptions are possible failures in electrical connectors or aging aspects of the bond used in the PZT patch and beams.

PZT3 shown in Figure 4c has a high variation point for damage 4 and a low point for damage 1 (baseline). Among the damage means, there was one beyond the standard of the points outside the limits as expected, once the damages were fixed. It is observed that the damage metric was able to measure the increase in intensity between the fixed damages with an increasing linear trend, that is, if there were six or more consecutive points of damage, there would be a non-random pattern in trend. Thus, as expected, there are several points outside the limits, showing the non-randomness of the damage with the pre-fixed damage. In conclusion, the impedance measure in the format of damage metric was able to assimilate the experiment built in the laboratory. Therefore, PZT3 proved to be a good structural damage detector.

PZT4 illustrated in Figure 4d shows that most of the mean points were outside the control limits for the mean chart. There was a greater shift in the damage metric1 (baseline) while for the other damages there was an increasing trend, except for damage 3 which was close to the value of the damage metric average 2. Regarding the monitoring of variability, it was observed less in damage 1 and greater in damage 2. 


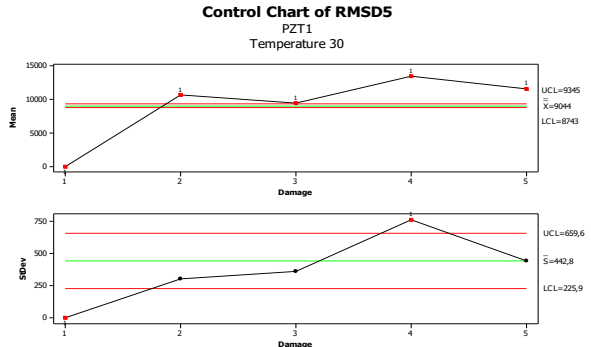

(a)
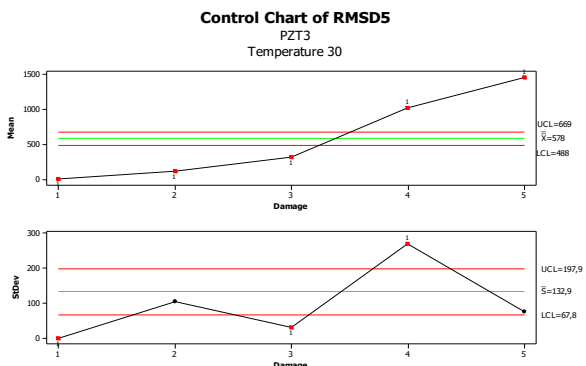

(c)
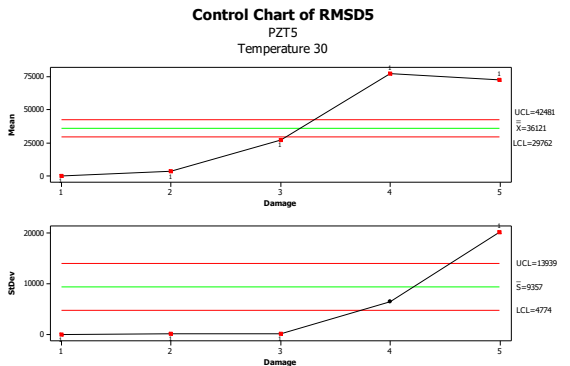

(e)
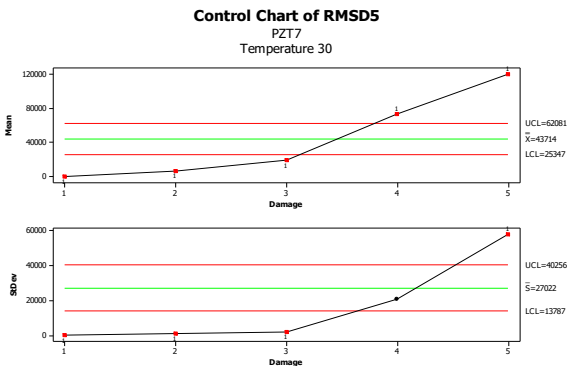

(g)

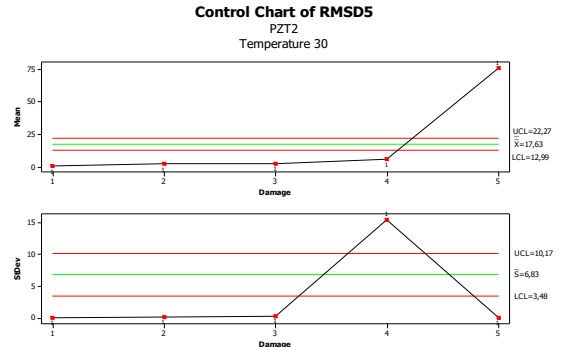

(b)

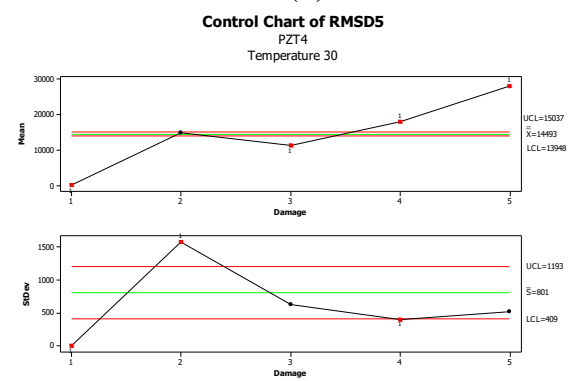

(d)

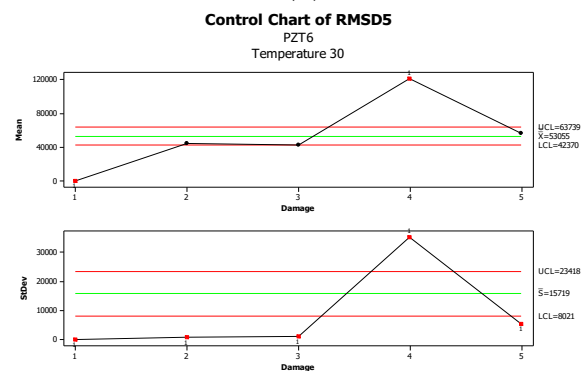

(f)
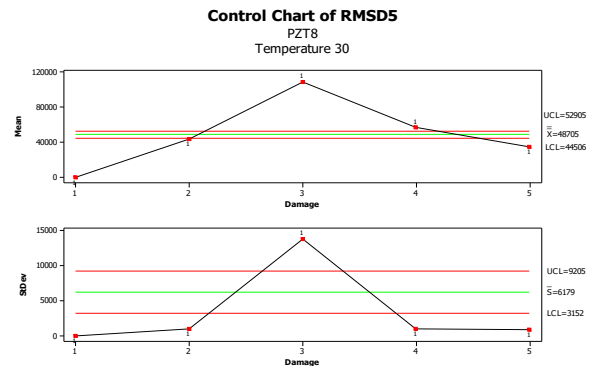

(h)

Figure 4 - Control charts of mean and standard deviation for RMSD5 damage metric for temperatures of 30 degrees Celsius for each PZT specimen. Results obtained using Minitab 14® software. 
PZT5 shown in Figure 4e has averages outside the limits and a small difference between the metrics in damage 1 and 2, with an increase in the metric from damage 3 with an average close to damage 4 . Concerning to the monitoring of variability, low variability was observed from damage 1 to damage 4 and a high variability in the metrics in damage 5. This high variation may be associated with the discrepant points observed by the boxplot in Figure 3.

PZT6 shown in Figure 4f has most averages within the control limits, damage 2, 3 and 5. This characterizes a non-differentiation between these damage metrics by this PZT. However, despite the proximity of the metrics among these damages, there is a differentiation in relation to damage 1 since it is outside the limits and much lower than the others. In conclusion, in this case at least one shift was detected in the metrics when compared to the baseline. Regarding the monitoring of variability, again, high variation was observed for damage 4 and low variability for other damages.

PZT7 illustrated in Figure 4g presents all midpoints outside the control limits, characterizing well the differentiation between the damages. Starting with damage 1 (baseline) at a low value for damage metric increasing up to damage 5, increasing its inclination after damage 4. Thus, PZT7 proved to be a good detector for high levels of damage. Regarding the monitoring of variability, there were low variations up to damage 4 and a peak for damage 5, possibly causing an outlier observed in the PZT7 boxplot in Figure 3.

PZT8 illustrated in Figure 4h shows all midpoints outside the control limits. In this case, damage 1 differed from the others, but peaked with a higher average of the damage metric of damage 3. In approximately the same proportion, there was a drop in the damage metric 4 and 5 , getting very close to the average damage values 2 and 5 . Regarding the monitoring of variability, low variation or standard deviations were observed in all damages, except for damage 3, which also had a peak of greater variability as in the mean. This variation may have been a cause of displacement of the average in this PZT, i.e., without this variation we could have had a PZT that differed damage and not damage, but failed to differentiate levels of damage.

Figure 5 presents the control charts for individual measurements and moving range of the RMSD5 damage metrics at temperature of 30 degrees. Also, each damage $(1,2,3,4$ and 5) was calculated considering damage 1 as the baseline.

PZT1 illustrated in Figure 5a presents a control chart for each damage of the individual measures of the damage metrics. In them, the lower and upper control limits for each measure in each damage stand out. It is possible to notice that no damage occurred outside the control limits. Remembering that points outside the limits indicate a non-random pattern. In this way, it can be said that observing the collected point to point, the data follow a randomness, since in addition to not having points outside, no other set of points was observed, causing non-randomness. The same is observed in the control chart for mobile amplitude. It is possible to highlight a greater variability in damage 4 due to the displacement of the average and the upper limit to a region above those seen for other damages.

The same did not happen for PZT2, Figure 5b. In addition to having points outside the control limits on damages 4 and 5, both for the individual measurements and moving range charts, one can also observe stagnation of the damage metrics values in almost all pre-fixed damages, changing only to damage 5 . This is a probable mechanical/electrical 
issue in PZT2 specimen with return of its activity at the end of the experiment. At this moment damage 5 was inserted. Therefore, in addition to the previous indications, this is also another argument for not trusting results returned by PZT2.

PZT3 illustrated in Figure 5c is similar to PZT1 with all points within the limits and without other non-random patterns. The greatest variation between the measures occurred in damage 4 . In addition, comparing the scale of the averages in relation to the baseline, the difference for damage 2 starts slowly, but increases to other damages 3,4 and 5 . In damage 3 , the control limits became very small with each point observed close to the average value.

In general, PZT4 shown in Figure 5d, in all damages (2 to 5), except baseline, has a greater variability than other PZTs. Also, in this chart there is a non-random pattern for damage 2 with more than six consecutive points below the midline, indicating a special cause. Comparing to the control chart of the standard deviation for this damage, it is observed that the point was outside the control limits, Figure $5 \mathrm{~d}$, thus getting an alert of improvement in the gathering of the data or in the refining of the pre-processing information with in order to reduce this variability. In monitoring the individual values, there was an increase in the greater metric for damage 5.

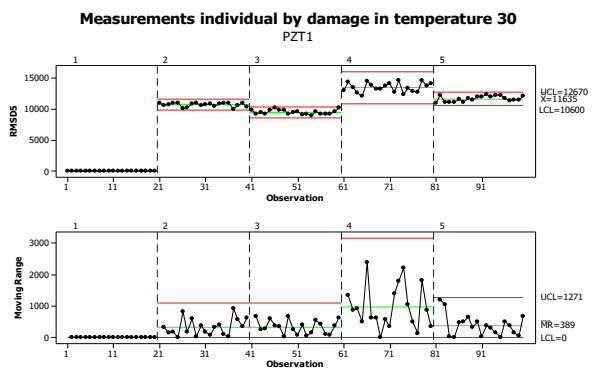

(a)

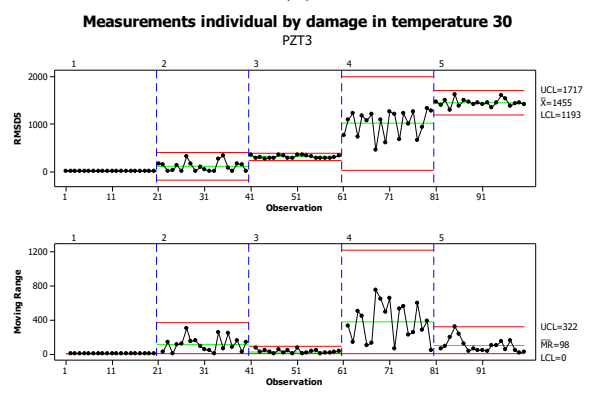

(c)
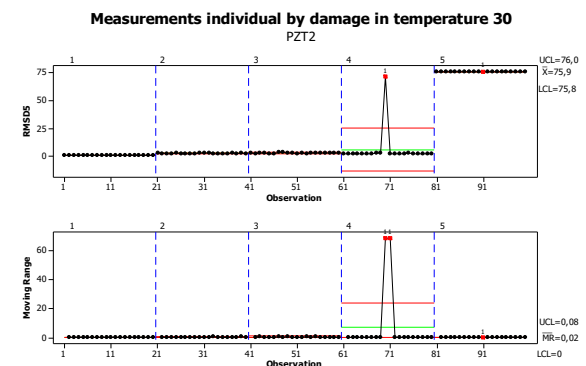

(b)

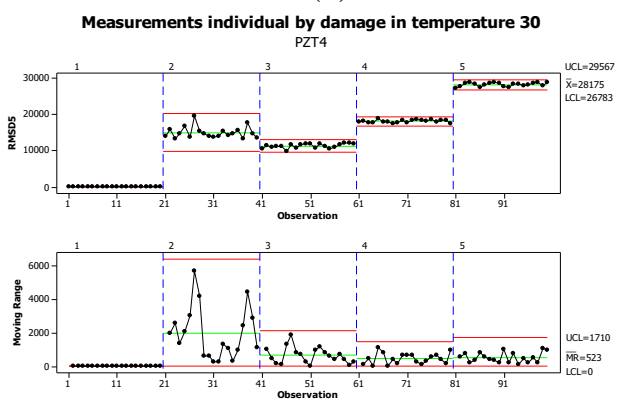

(d)

Figure 5 - Control charts for individual and moving range measurements for RMSD5 damage metric for temperatures of 30 degrees for each PZT patch. Results obtained using Minitab 14® software. 
Figure 5e-g shows the PZTs 5, 6 and 7. The control graphs behaved similarly, with greater variability for damages 4 and 5 . In these cases, all points were within the control limits. Due to the low variability in damage 1 to 3 , as soon as the control limits are very close some point was detected outside the limit. However, in this case, due to the low variability in the moving range, it did not become a warning.

Finally, PZT8, Figure 5h, showed greater variation in damage 3 with a higher average than others. Thus, there was an increase in the baseline damage metric, damage1, up to damage 3 , and then, a decrease until damage 5 , with very small variations between the points in that damage.

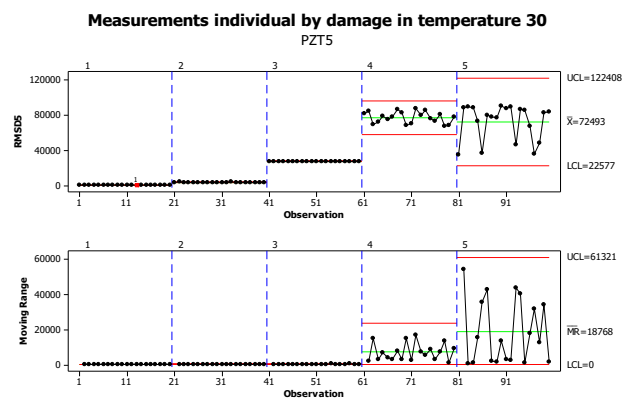

(e)

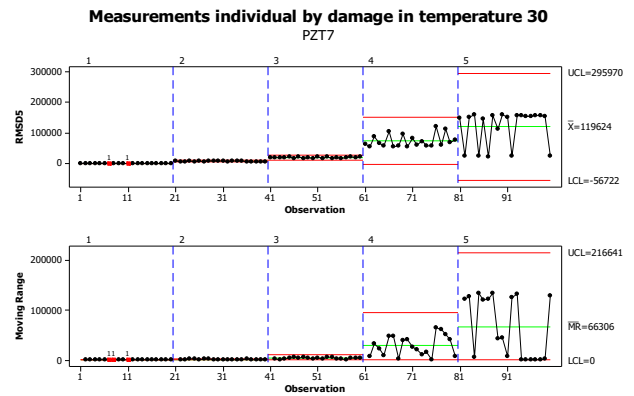

(g)
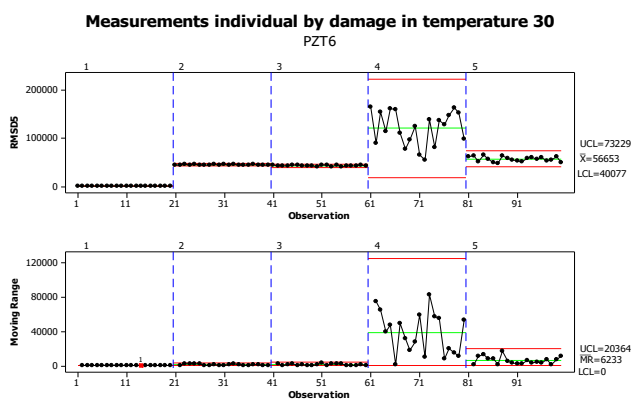

(f)
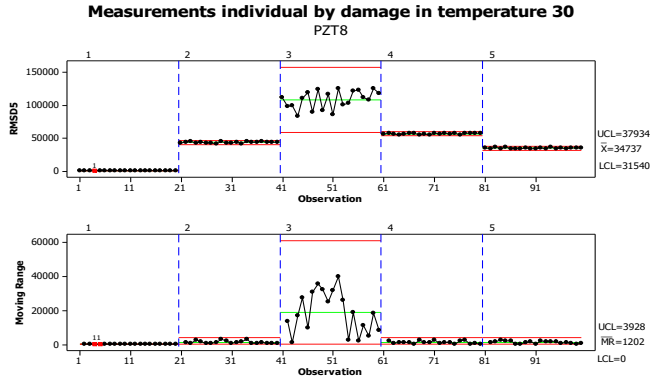

(h)

Figure 5 (Continuation) - Control charts for individual and moving range measurements for RMSD5 damage metric for temperatures of 30 degrees for each PZT patch. Results obtained using Minitab 14® software.

\section{Conclusions}

SPC proved to be a good approach for descriptive analysis and data pre-processing. It identified temperatures with better repeatability and reproducibility and within this range it was possible to find PZT2 with problems in the impedance readings and it was also possible 
to better visualize the behavior of the joint or individual variation of the metrics, average standard deviation or moving range, respectively. Also contributed to the analysis of the displacement of observations around the mean, finding patterns of non-randomness that could be a possible problem of data gathering. Concluding, further suggested analysis will be the implementation of identification and remoting of outliers, repeating a new $R \& R$ study and monitoring of mean and variability.

\section{Acknowledgments}

All authors thank to Petroleo Brasileiro S.A. (Petrobras) due to the support in this project. Also, the authors would like to thank editors and reviewers for their comments and suggestions.

NOMELINI, Q. S. S., SILVA, J. W., GALLO, C. A., FINZI NETO, R. M., MOURA JUNIOR, J. R. V. Controle estatístico de processos (CEP) de métricas de danos em monitoramento de estruturas de saúde. Rev. Bras. Biom. Lavras, v.39, n.1, p.7-24, 2021.

- RESUMO: Controle Estatístico de Processos (CEP) se fundamenta no uso de cartas de controle e técnicas de repetibilidade e reprodutibilidade (estudo $R \& R$ ). Este trabalho busca a aplicação destas ferramentas no pré-processamento de dados no monitoramento estrutural. $O$ experimento foi conduzido em um delineamento inteiramente casualizado com duas fontes de variação: oito vigas de alumínio com pastilhas piezelétricas coladas como sensores e cinco tipos de danos (DI = integra, $D 2=0,6 \mathrm{~g}, \mathrm{D} 3=1,1 \mathrm{~g}, \mathrm{D} 4=1,6 \mathrm{~g}$ e D5 = 2,2g). Todas medidas foram obtidas a $30^{\circ} \mathrm{Ce}$ com 20 repetições para cada condição, produzindo uma métrica de dano. No estudo $R \& R$ uma baixa variação de repetição foi observada (9,84\%), mas uma elevada reprodutibilidade (72,39\%), representando que as métricas de dano foram similares para cada situação, mas uma alta variação entre vigas e níveis de danos. Baseado nesta avaliação as cartas de controle auxiliaram na verificação de quais vigas e níveis de danos haviam mais variabilidade. Concluindo, as cartas de controle para médias e medidas individuais, assim como estudo $R \& R$ são ferramentas interessantes para a etapa de pré-processamento de dados brutos com objetivo de detecção de erros de medidas.

- PALAVRAS-CHAVES: Cartas de controle; estudo R\&R; monitoramento da integridade estrutural.

\section{References}

ALMAS, F. Implementação de controle estatístico de processos em uma empresa têxtil. 2003. 120f. Dissertação (Mestrado em Engenharia de Produção) - Universidade Federal de Itajubá, Itajubá, 2003.

AUTOMOTIVE INDUSTRY ACTION GROUP (AIAG). Measurement Systems Analysis Reference Manual, 3.ed. Chrysler, Ford, General Motors Supplier Quality Requirements Task Force, 2002

DEMING, W. E. Qualidade: a revolução da administração. Rio de Janeiro: Marques Saraiva, 1990. 367p.

HICKS, C. R. Fundamental concepts in the design of experiments. 2.ed. New York: Holt, Rinehart and Winston, 1973. 349p. 
KUME, H. Métodos estatísticos para melhoria da qualidade. São Paulo: Editora Gente, 1993. 245p.

MINITAB® RELEASE 14 for Windows. Copyright 1972-2004.

MONTGOMERY, D. C. Introdução ao controle estatístico da qualidade. 7.ed. Rio de Janeiro: LTC, 2016. 572p.

NETER, J.; WASSERMAN, W.; KUTNER, M. H. Applied linear statistical models. 2.ed. Irwin: USA, 1985. 1127p.

NOMELINI, Q. S. S. Padrões de não-aleatoriedade no controle estatístico de processo. 2007. 182f. Dissertação (Mestrado em Estatística e Experimentação Agropecuária) Departamento de Ciências Exatas (DEX), Universidade Federal de Lavras, Lavras, 2007.

NOMELINI, Q. S. S. Enfoque estatístico na validação de métodos para teste de germinação de sementes florestais. 2012. 163f. Tese (Doutorado em Agronomia) Universidade Federal de Uberlândia, Uberlândia, 2012.

PEAIRS, D. M. High frequency modeling and experimental analysis for implementation of impedance-based structural health monitoring. 2006. 150f. Tese (Doutorado) - Virginia Polytechnic Institute and State University, 2006.

PINTO JÚNIOR, D. L. Repetitividade e reprodutibilidade de sistemas de medição. In: $36^{\circ}$ REUNIÃO REGIONAL DA ASSOCIAÇÃO BRASILEIRA DE ESTATÍSTICA, 36, 2003, João Pessoa. Anais... João Pessoa: UFPB, 2003. p.106.

STEEL, R. G. D.; TORRIE, J. H. Principles and procedures of statistics: a biometrical approach. New York: Mc-Graw Hill, 1981. 633p.

VEIT, E. O controle estatístico de processos na indústria de cabinagem de Veículos: um estudo de caso. 2003. 104f. Dissertação (Mestrado em Engenharia de Produção) Universidade Federal de Santa Catarina, Florianópolis, 2003.

WERKEMA, M. C. C. Ferramentas estatísticas básicas para o gerenciamento de processos. 2.ed. Belo Horizonte: QFCO, 1995. 210p.

Received on 26.06.2020

Approved after revised on 28.01.2021 